\title{
Stoichiometric Combustion Model with Oxygen Threshold Improved Predictions for Fire Simulation Using a CFD Model
}

\author{
MINGCHUN LUO and VAUGHAN BECK \\ Centre for Environmental Safety and Risk Engineering \\ Victoria University of Technology \\ PO Box 14428 \\ MCMC, Melbourne, Victoria 8001, Australia
}

\begin{abstract}
This paper examines the effect of various combustion models when predicting the environment in a building arising from fire in a room. The use of a stoichiometric combustion model will usually over-predict the efficiency of the combustion process in the fuel-rich areas and hence over-predict the temperature field. A modified combustion model presented in this paper can improve the predicted results of fire simulation when using a computational fluid dynamics (CFD) model. The modified model is based on the stoichiometric method, but where an oxygen threshold is introduced. The modified model is applied to a CFD program, called the CESARE-CFD fire model, and the results obtained were compared with the experimental results. It was found that the predicted results, using the modified combustion model, gave improved results which were in reasonable agreement with experimental results.
\end{abstract}

KEY WORDS: Combustion Model, Field Model, Fire

\section{NOTATION}

$\mathrm{a}, \mathrm{b} \quad$ stoichiometric coefficient of $\mathrm{CO}$ and $\mathrm{CO}_{2}$

f mixture fraction

$r \quad$ stoichiometric ratio of oxygen to fuel

Y mass fraction

$\mathrm{Y}_{\mathrm{O} 2 \text {, Id }}$ threshold of oxygen concentration

$\Phi \quad$ conserved property defined in Eq. 1

\section{Subscript}

f fuel

0 in air stream

s stoichiometric

1 in fuel stream 


\section{INTRODUCTION}

Combustion in the gas phase is a complicated process which is controlled by gas mixing or chemical reaction kinetics. With the mixture-fraction concept, the stoichiometric combustion model is widely used for the calculation of turbulent diffusion flames in computational fluid dynamics (CFD) model [1-3]. With this concept, it is assumed that the rate of combustion is limited by gas phase mixing; namely that the chemical kinetics rates are much faster than the gas mixing and that all species have the same diffusivity; that is, the exchange coefficients for the fuel and oxidant are equal.

A simple one-step reaction is used to describe the gas combustion model. Namely a unit mass of fuel combines with the required stoichiometric mass of oxygen, $m_{O}$, to give $1+m_{O}$ mass of products. Nitrogen is assumed to act as a diluent and does not take part in the reaction. The local combustion reaction is assumed to occur instantaneously.

The fuel and oxidant are assumed to unite always in their stoichiometric proportions with intermediate species being ignored. The reaction of the fuel gas with the oxidant is a one-step process which is infinitely fast compared with the mixing rates. This method enable a simple representation of the combustion situation in a CFD model. However, in fuel-rich areas, the model over-predicts the efficiency of the combustion process and the predicted temperatures in fuel-rich areas (plume areas in fires and hot layers) are higher than the measured temperatures [4-5]. The reasons for this are discussed successively. In this study, the oxygen threshold concept is introduced into the combustion process. While the combustion model retains its simplicity, it was found that the predicted results were significantly improved.

\section{THEORETICAL MODEL}

\section{Combustion Model}

The calculation of combustion process with the mixture-fraction concept is based on a simple one-step reaction assumption. The combustion model in the simple chemically reacting system was summarised by Lockwood and Naguib [6]. A conserved property (the quantity, $\Phi$ ) of the flow under chemical reaction is defined as follows:

$$
\Phi=\mathrm{Y}_{\mathrm{f}}-(1 / \mathrm{r}) \mathrm{Y}_{\mathrm{O} 2}
$$

where $Y_{f}$ is the mass fractions of fuel; $Y_{O 2}$ is the mass fraction of oxidant; $r$ is the stoichiometric oxidant requirement to burn $1 \mathrm{~kg}$ fuel. Then the mixture fraction, $\mathrm{f}$, at any point is expressed as:

$$
\mathrm{f} \equiv\left(\Phi-\Phi_{1}\right) /\left(\Phi_{\circ}-\Phi_{1}\right)
$$

where $\Phi_{\mathrm{O}}$ and $\Phi_{1}$ are, respectively, the values of $\Phi$ in oxidant and fuel. Provided that the rate of combustion is infinitely fast compared with the mixing rates and the reaction is complete, the modelled species relations vs mixture fraction for the simple combustion model are expressed as follows: 


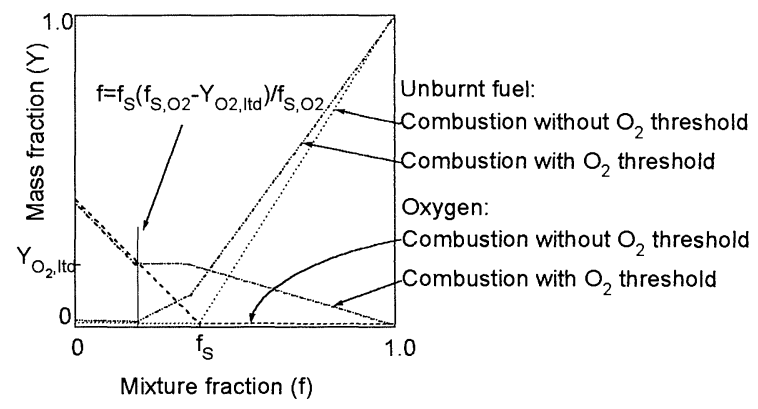

FIGURE 1 Sketch of the combustion model with and without oxygen threshold

$0 \leq \mathrm{f} \leq \mathrm{f}_{\mathrm{s}} \quad: \quad \mathrm{Y}_{\mathrm{f}}=0.0, \quad \mathrm{Y}_{\mathrm{O} 2}=\mathrm{Y}_{\mathrm{O}, 0}\left(\mathrm{f}_{\mathrm{s}}-\mathrm{f}\right) / \mathrm{f}_{\mathrm{s}}$

$f_{s} \leq f \leq 1 \quad: \quad Y_{f}=Y_{f, 1}\left(f-f_{s}\right) /\left(1-f_{s}\right), \quad Y_{O 2}=0.0$

where $\mathrm{f}_{\mathrm{s}}$ is a value of the mixture fraction at which the concentrations of fuel and oxygen are in stoichiometric proportion; $\mathrm{Y}_{\mathrm{O} 2,0}$ is the concentration of oxygen in the oxidant stream (air); $\mathrm{Y}_{\mathrm{f}, 1}$ is the concentration of fuel in the fuel stream (usually $Y_{f, 1}=1.0$ and $Y_{02,0}=0.233$ ). The mass fractions of oxygen and unburnt fuel against the mixture fraction of fuel are sketched in Fig. 1 and are marked as combustion without $\mathrm{O}_{2}$ threshold. In this model, the combustion efficiency has not been considered; the combustion process would proceed if any oxygen exists until all the fuel were totally burnt. In realistic situations, however, the combustion process will extinguish [7] or will change from flaming to non-flaming situation [8] when the oxygen concentration is reduced below some certain level (say, $10 \%$ ). So this model usually overpredicts the gas temperatures especially in plume areas where the fuel concentration is relatively high.

To overcome the over-prediction of temperatures in the plume areas, a threshold oxygen concentration, $\mathrm{Y}_{\mathrm{O} 2 \text {, Itd, }}$ is introduced such that the fuel will cease to burn when oxygen concentration is below this threshold. The concentrations of oxygen and fuel were modelled using the following procedure:

1. Estimate the oxygen requirement in stoichiometric proportion $f_{\mathrm{S}, \mathrm{O} 2}$ and mass fraction of oxygen in mixture $\mathrm{f}_{\mathrm{O} 2}$.

$$
\begin{aligned}
& \mathrm{f}_{\mathrm{s}, \mathrm{O} 2}=\left(1.0-\mathrm{f}_{\mathrm{s}}\right) \times \mathrm{Y}_{\mathrm{O} 2,0} \\
& \mathrm{fO}_{\mathrm{O} 2}=(1.0-\mathrm{f}) \times \mathrm{Y}_{\mathrm{O} 2,0}
\end{aligned}
$$

2. Calculate the concentrations of oxygen and unburnt fuel at the stage of $0.0 \leq \mathrm{f} \leq \mathrm{fs}_{\mathrm{s}}\left(\mathrm{fs}_{\mathrm{s}, 02}-\mathrm{Y}_{02, \mathrm{ltd}}\right) / \mathrm{fs}_{\mathrm{s}, 02}$ in which all fuel will burn. So we have:

$$
Y_{\mathrm{f}}=0.0, \quad Y_{02}=Y_{02,0}\left(f_{s}-f\right) / f_{s}
$$


3. Calculate the concentrations of oxygen and unburnt fuel at the stage of $\mathrm{f} \geq \mathrm{fs}_{\mathrm{s}}\left(\mathrm{f}_{\mathrm{s}, \mathrm{O} 2}-\mathrm{Y}_{\mathrm{O} 2, \mathrm{lt}}\right) / \mathrm{fs}_{\mathrm{s}, \mathrm{O} 2}$ and $\mathrm{f}_{\mathrm{O} 2} \geq \mathrm{Y}_{\mathrm{O} 2 \text {, Itd }}$ where part of the fuel will burn and the oxygen concentration will remain at the $\mathrm{Y}_{\mathrm{O} \text {, ltd }}$ level. Then:

$$
Y_{f}=Y_{f, 1}\left(f-\left(f_{02}-Y_{O 2, \text { ltd }}\right) f_{s} / f_{s, 02}\right) \text { and } Y_{O 2}=Y_{O 2, \text { ltd }}
$$

4. Evaluate the concentrations of oxygen and unburnt fuel when $f_{\mathrm{O} 2} \leq \mathrm{Y}_{\mathrm{O} 2 \text {,Itd }}$; since the oxygen concentration is lower than the oxygen threshold, no combustion is assumed. So,

$$
\mathrm{Y}_{\mathrm{f}}=\mathrm{f} \times \mathrm{Y}_{\mathrm{f}, 1} \quad \text { and } \quad \mathrm{Y}_{\mathrm{O} 2}=(1.0-\mathrm{f}) \mathrm{Y}_{\mathrm{O} 2,0}
$$

The mass fractions of oxygen and unburnt fuel vs fuel mixture fraction are also illustrated in Fig. 1 so as to compare with the original combustion model. The differences between the modified combustion model and the original combustion model can be seen when the mixture fraction of fuel $f>f_{s}\left(f_{s, O 2}-Y_{O 2, \text { ttd }}\right) / f_{s, 02}$. When the threshold of oxygen, $Y_{O 2, \text { Itd }}$, set to be zero, the modified combustion model becomes the original model.

The burning characteristics of a fire under low oxygen concentrations are not well understood. In this study, the oxygen threshold level was set at $10 \%$, based on the empirical findings of Tsuchiya and Mathieu [8]. The choice of this value and the adopted modelling approach will usually have effects on the calculation of the combustion process in the plume area where the fuel concentration is high.

\section{CFD Model}

The modified combustion model has applied to an existing CFD program, namely the CESARE-CFD fire model. This model is based on a commercial code FURNACE which was originally developed for the modelling of pulverised coal-fired boiler and pool fires [4,9] and was further developed for the simulation of realistic building fires at the Centre for Environmental and Risk Engineering (CESARE), Victoria University of Technology (VUT), Australia. The CESARE-CFD fire model is like many other field models in that it numerically solves the basic Navier-Stokes conservation equations in three dimensions for a number of fluid properties. These include the momentum, energy and mass conservation equations. Turbulence is modelled using $k-\varepsilon$ model, with conservation of turbulent energy $(k)$ and the dissipation rate of turbulent energy $(\varepsilon)$. This model has been discussed in greater details in Refs [9] and [10].

\section{Radiation and Species Calculation}

A radiation sub-model was included into the CESARE-CFD program which uses the discrete transfer method [11]. This method is based on the solution of representative directed beams of radiation within the computational domain. The ray directions were specified in advance and were solved between two boundary walls. The absorption coefficient was calculated by considering the local concentrations of $\mathrm{CO}_{2}, \mathrm{H}_{2} \mathrm{O}$ and soot [12]. Soot formation in turbulent flames assumes that the soot particle is formed from the gas phase in two stages. The first 
stage concerns the formation of radical nuclei and the second stage concerns the soot particle formation from these nuclei [13].

The mixture fraction is governed by the equation of mass conservation. The consumption of oxygen and fuel in the gas phase follows the stoichiometric ratios with oxygen threshold. The local oxygen concentration and the unburnt fuel can be estimated by Eqs (5-9) given previously.

$\mathrm{CO}$ is the major toxic gas during building fires. To assess the level of fire safety, it is essential to predict correctly the distribution of $\mathrm{CO}$ and $\mathrm{CO}_{2}$ which are the products of combustion. For polyurethane, $\mathrm{CO}$ and $\mathrm{CO}_{2}$ can be calculated by the chemical reaction equation given as follows:

$$
\begin{aligned}
\mathrm{CH}_{1.91} \mathrm{O}_{0.263} \mathrm{~N}_{0.055}+(0.5 a+b+0.346+ & 0.028 \mathrm{x}) \mathrm{O}_{2} \\
& \rightarrow a \mathrm{CO}+b \mathrm{CO}_{2}+0.955 \mathrm{H}_{2} \mathrm{O}+0.055 \mathrm{NO}_{\mathrm{x}}
\end{aligned}
$$

The prediction of $\mathrm{CO}_{2}$ is based on the mass balance of consumed carbon in the fuel and the $\mathrm{CO}$ concentration is calculated from empirical correlation between $\mathrm{CO}$ and $\mathrm{CO}_{2}[7,14]$.

$$
\frac{Y_{C O}}{Y_{\mathrm{CO}_{2}}}=\frac{28 a}{44 b} \text { and } \quad \frac{44 b}{28 a}=\frac{60 Y_{\mathrm{O}_{2}}}{23}
$$

\section{EXPERIMENTAL SET-UP AND INSTRUMENTATION}

Experiments were carried out in the Centre's Experimental Building-Fire Facility (EBFF), which is a multi-enclosure, multi-storey building. The basic structure of the facility is a $21 \times 16 \times$ $12 \mathrm{~m}$ high steel frame and concrete slabs. Part of the experimental facility has been fitted out to represent portion of a multi-storey apartment building. Each level of this building comprises four rooms with a corridor which connects the apartment with the stair and lift. The building contains a lift shaft, a stair shaft and air handling shafts. Three rooms and a part of the corridor on the first level were involved in this study. An ASTM standard burn room, Room 2 $(3.6 \times 2.4 \times 2.4 \mathrm{~m}$ high) is located on the first level. The adjacent rooms are, Room 1 $(2.4 \times 4.9 \times 2.4 \mathrm{~m}$ high), Room $3(2.8 \times 3.6 \times 2.4 \mathrm{~m})$. The corridor connects the apartment to the outside of the building. The layout of the first level of the EBFF is illustrated in Fig. 2. The EBFF was equipped with instruments to measure temperature, radiation, gas composition and smoke optical density. The measured data were collected using a PC-based data logger.

A total of 128 thermocouples were allocated at four different elevations (32 thermocouples located at each elevation) in the three rooms and the corridor (see Fig. 2). These four elevations were $0.25,0.75,1.2$, and $1.4 \mathrm{~m}$ from the ceiling. The thermocouples were placed on frames which were hung from the ceiling of each room and corridor.

One radiation fluxmeter was located on the floor of the burn room near the door area. The radiometer was a heat flux transducer and water cooled; the capacity of the radiometer was 56 $\mathrm{kW} / \mathrm{m}^{2}$. Instrumentation to record chemical analysis of $\mathrm{CO}, \mathrm{CO}_{2}$ and $\mathrm{O}_{2}$ was installed in the facility. During experiments, gas samples were taken at the centre of each room (1.9 $\mathrm{m}$ above 


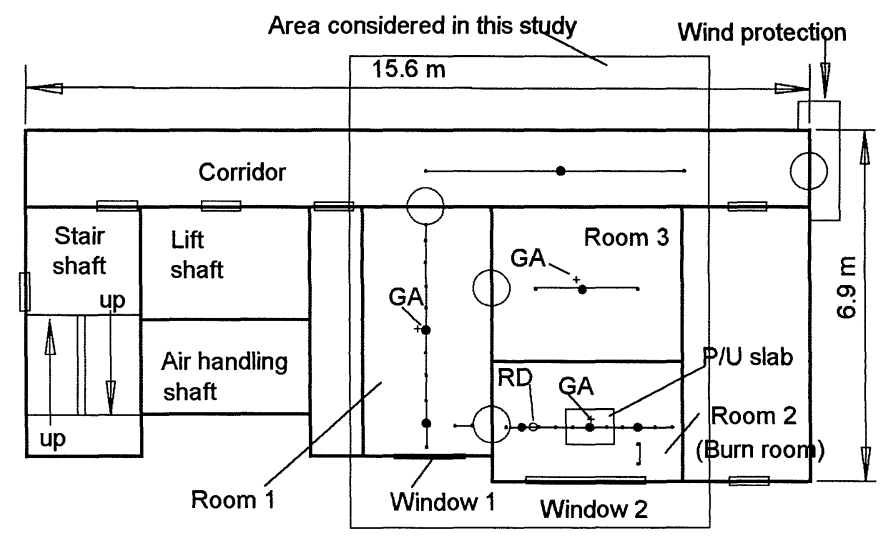

: Open door; $\longleftarrow$ : Door sealed in this study; $\quad \ldots$ : Thermocouple frame;

- : Position reported in this study; $\quad$ GA+ : Gas sampling; RD O: Radiometer;

FIGURE 2 Layout of the Experimental Building-Fire Facility and instrumentation

the floor). A weighing system was used to record the mass on a floor platform in the burn room during the fire; the mass release rate was deduced from the recorded mass.

A polyurethane slab was used as the fuel in the experiments. The total fuel weight was $3.10 \mathrm{~kg}$. The slab was standard polyurethane foam which was placed horizontally at the centre of the burn room on an open-mesh steel frame and ignited with a standard electrical igniter [15] placed at the centre of the slab. The slab ignited (flaming) instantaneously when the electrical igniter was placed in contact with the slab surface; the igniter was then removed.

\section{RESULTS}

In the experiments, the slab was ignited at the centre of polyurethane slab and the fire developed slowly at its early stage ( 1 to 2 minutes). The fire lasted for about 7 minutes. The residual mass of the polyurethane foam was measured with the weighing system. The mass release rate was then deduced and plotted in Fig. 3.

In CFD modelling, an initial flow field was established by inducing a small amount of air at the centre of burn room on the floor under steady-state conditions. The converged results were then used as initial values for the transient-state simulation. In the CESARE-CFD fire model, the slab was simplified as a cylinder $0.52 \mathrm{~m}$ in radius $(3.1 \mathrm{~kg}$ ). Fire was started at the centre of the cylinder. The measured mass release rate was used as an input for the CFD model. The volume of three rooms and part of the corridor was divided into a $40 \times 41 \times 15$ node Cartesian mesh. A SPARC 10 server was used for the computational work. It took about 100 hours of CPU time to simulate 10 minutes of the real fire including the time to set the initial flow field.

Two simulations were carried out in this study; one was using the original combustion model without the oxygen threshold assumption and another using the modified combustion model in 


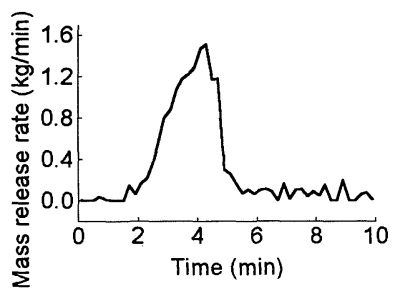

FIGURE 3 Measured mass release rate

which an oxygen threshold was applied. The results obtained from these two simulations were then compared with the experimental results.

\section{Gas Temperature}

The thermocouples were located in three rooms and the corridor to measure gas temperatures. Reported in this section is a comparison of the measured temperatures from 14 representative points with the results of two runs of CFD model predictions using different combustion models. There were six points in the burn room (three in the upper level, $1.65 \mathrm{~m}$ above the floor, and three in the lower level, $1 \mathrm{~m}$ above the floor), four in Room 1 (two in the upper level, $1.65 \mathrm{~m}$ above the floor, and two in the lower level, $1 \mathrm{~m}$ above the floor), and there were two in Room 3 and two in the corridor (one in the upper level and one in the lower level). The results obtained from the 128 thermocouple measuring points are also compared with the predicted results at certain time steps.

Figure 4 gives the temperature histories in the burn room at 6 different locations. Figures 4(a), (b) and (c) show the predicted and measured temperatures in the upper level $(1.65 \mathrm{~m}$ above the floor); Figures 4(d), (e) and (f) depict the temperatures in the lower level (1 m above the floor). Comparing the predicted temperatures using the modified combustion model with the predicted results of the combustion model without the oxygen threshold, the modified model predicted much lower peak temperatures $\left(400^{\circ} \mathrm{C}\right.$ lower) compared with that of the original

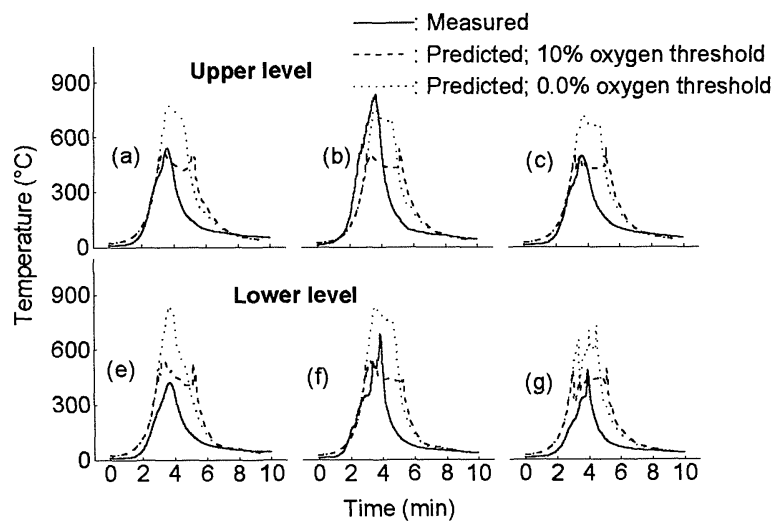

FIGURE 4 Measured and Predicted temperatures in Room 2 (burn room) 


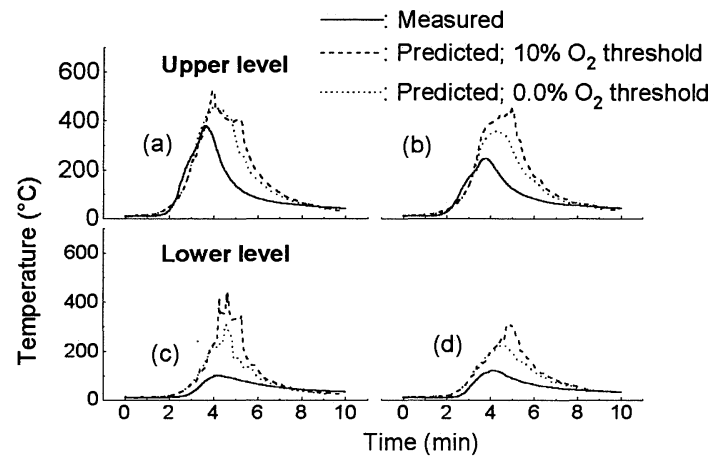

FIGURE 5 Measured and predicted temperatures in Room 1 (adjacent room)

combustion model during the main combustion period (3-4 minutes). The peak temperatures from the modified combustion model are in good agreement with the experimental results except in Fig. 4(b).

Figure 5 describes the temperature histories at four locations in Room 1 (Figs. 5(a) and (b) for the upper level, Figs. 5(c) and (d) for the lower level). Figures 5(a) and (c) present the modelling and experimental results near the door of the burn room; Figures 5(b) and (d) depict the results at the centre of this room. Figure 6 depicts the temperature histories at two locations in Room 3 and at two locations in the corridor. Both with and without the oxygen threshold in the combustion model, the CESARE-CFD fire model over-predicted the gas temperatures in Room 1 and Room 3 during the main combustion period (3-5 minutes). The model predictions and the measurements are in reasonable agreement in the corridor.

Figures 7 illustrates the overall comparison of the measured and predicted temperatures at 2 5 minutes; these time steps represent the earlier, main and later stages of fire development of the experiment respectively. In total, there are 128 measured points in Room 2 (the burn room), Room 1 (the adjacent room), Room 3 (the next room) and the corridor. Figures 7(a) and (b) show that the predicted temperatures are not affected by the introduction of the oxygen

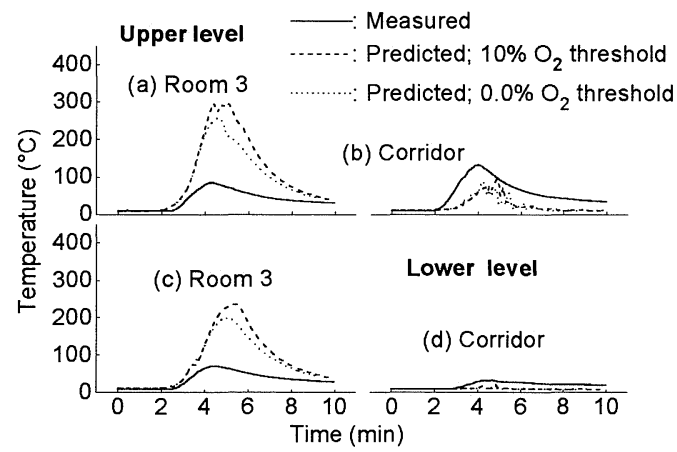

FIGURE 6 Measured and predicted temperatures in Room 3 (next room) and Corridor 


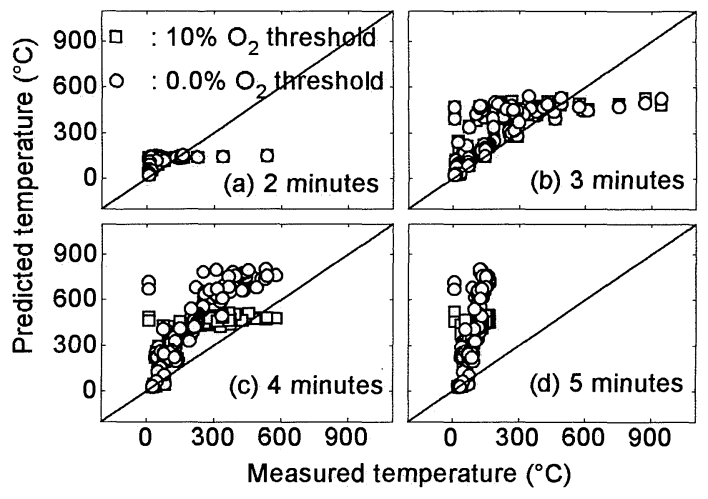

FIGURE 7 Overall comparison of measured and predicted temperatures

threshold at these stages. The CFD results are in reasonable agreement with the experimental results. At the time of 4 and 5 minutes (Figs 7(c) and (d)), the use of the oxygen threshold approach in combustion model significantly improved the CFD model results even though the modified combustion model still over-predicted the experimental results.

\section{Gas Compositions and Radiation Heat Flux}

Three gas sampling probes were located at the centre of Rooms 1, 2 and 3 (1.9 m above the floor). Measurement of oxygen and carbon dioxide was taken in each of these three rooms. The measurement of carbon monoxide was only available for the burn room. The predicted and

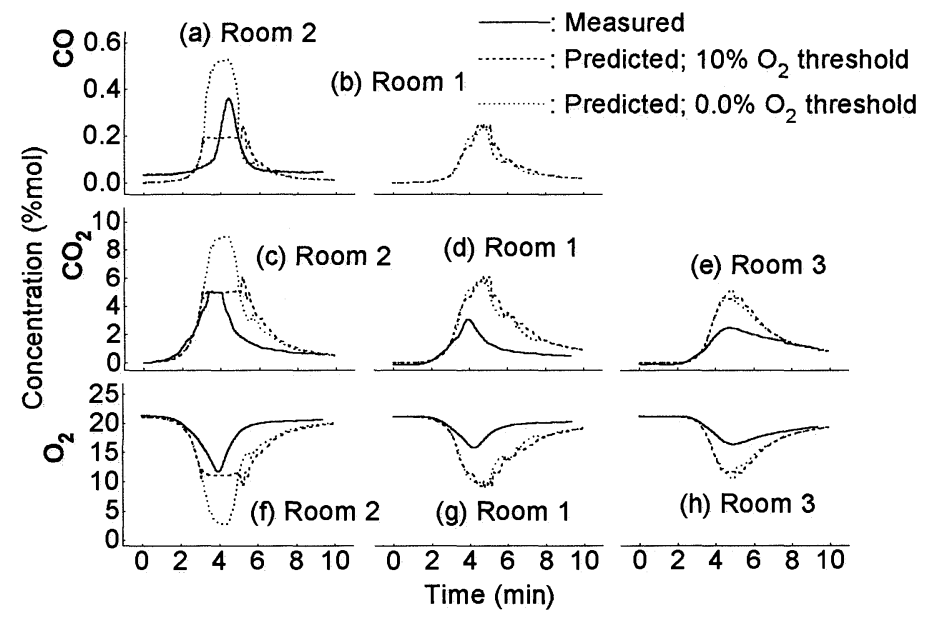

FIGURE 8 Measured and predicted $\mathrm{CO}, \mathrm{CO}_{2}$ and $\mathrm{O}_{2}$ concentrations 


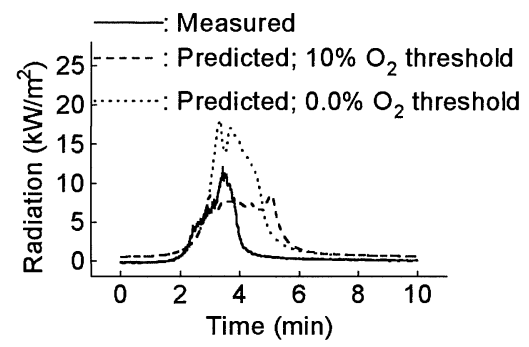

FIGURE 9 Measured and predicted radiation heat flux on the floor of burn room

measured results are given in Fig. 8. Again, the modified combustion model had a significant effect on the predicted results in the burn room during the period of 3-5 minutes. The modified combustion model gave a closer prediction of the experimental results than the original combustion model.

The radiation heat flux history on the floor of the burn room (Fig. 2) is given in Fig. 9. Two combustion models predicted the same trend during 0-3 minutes and after 5 minutes. During 35 minutes, the results for both the modified combustion model and the original combustion model deviated from the measured results. The modified model improved the CFD model prediction.

\section{DISCUSSION}

The modelling results clearly reflect the effect of the combustion model. At the early stage of the fire, the mass release rate from the fire was relatively low (Fig. 3), hence the mixture fraction of fuel was lower than the stoichiometric proportion $\left(0 \leq \mathrm{f} \leq \mathrm{f}_{\mathrm{s}}\left(\mathrm{f}_{\mathrm{s}, \mathrm{O}}-\mathrm{Y}_{\mathrm{O} 2, \mathrm{ltd}}\right) / \mathrm{f}_{\mathrm{s}, \mathrm{O}}\right)$. Both the original combustion model and the modified combustion model predicted that the unburnt fuel in gas phase was zero and the mass fraction of oxygen in gas phase followed the same track (Fig. 1). Accordingly, the predicted results from two combustion models overlaid each other and were close to the experimental results.

During the main combustion period (3-5 minutes), the mass release rate reached a maximum. In the burn room, the mixture fraction of fuel was close to the stoichiometric proportion and the oxygen concentration in the mixture $\left(\mathrm{f}_{\mathrm{O} 2}\right)$ was higher than the oxygen threshold, $\mathrm{Y}_{\mathrm{O} 2 \text {,It }}$, i.e.,

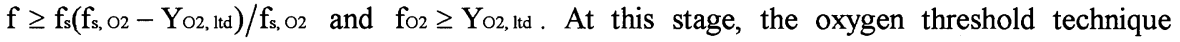
produced a reduced overall combustion rate in the burn room. As shown in Fig. 1, the oxygen mass fraction in gas phase remained at $\mathrm{Y}_{\mathrm{O} \text {,Itd }}$ level; the concentration of unburnt fuel increased, hence the burning of the fuel in gas phase was reduced compared with the case where there was no oxygen threshold assumption. During this period, the modified combustion model gave much lower temperatures, lower $\mathrm{CO}$ and $\mathrm{CO}_{2}$ concentrations and higher $\mathrm{O}_{2}$ concentration than the original combustion model in the burn room; the results were in reasonable agreement with the experimental results.

In Rooms 1 and 3, the predicted results obtained from both combustion models gave a similar trend since the mixture fraction of fuel fell into the range of $0 \leq \mathrm{f} \leq \mathrm{f}_{\mathrm{s}}\left(\mathrm{f}_{\mathrm{s}, \mathrm{O} 2}-\mathrm{Y}_{\mathrm{O} 2, \mathrm{td}}\right) / \mathrm{f}_{\mathrm{s}, \mathrm{O} 2}$ 
during the fire. The calculated temperatures during the period of 3-5 minutes from the modified combustion model were slightly higher than those from the original model, since during the same period, the modified combustion model predicted higher unburnt fuel in gas phase in the burn room than the original combustion model. This unburnt fuel is then transported to Rooms 1 and 3 and burnt in these spaces. For the same reason, the modified combustion model predicted slightly lower oxygen concentration and slightly higher carbon monoxide and carbon dioxide concentrations when compared with the original model in these spaces.

Significant discrepancies between the experimental results and the predicted results existed in Rooms 1 and 3. In the CESARE-CFD fire model, a mixture-fraction formulation was used. The model predicts the fuel distributions in the burn room and the adjacent enclosures; the local temperature is then calculated according to the local fuel concentration. For the real fire situation, however, combustion mainly occurs in the burn room; the combustion products and the unburnt fuel transfer to the adjacent enclosures. During the experiment, no combustion process was observed in Rooms 1 and 3. So the CFD model using both the modified and original combustion models over-predicts the measured temperatures and the concentrations of combustion products in the adjacent enclosures during the main combustion period. After 5 minutes, the predictions from two combustion models were generally close to each other in all spaces. At this stage, the mixture fraction of fuel lays on a lower level; the oxygen threshold technique in the combustion model does not affect the evaluation of the combustion process.

In general, the modified combustion model with the oxygen threshold assumption significantly improved the CFD model predicted results. The model results obtained from the CESARECFD fire model, including the oxygen threshold assumption, were in reasonable agreement with the experimental results.

\section{CONCLUSION AND RECOMMENDATION}

A modified combustion model is based on the stoichiometric combustion model with the mixture-fraction concept and an oxygen threshold assumption has been introduced to simulate the combustion process. The modified model was applied to an existing CFD model, CESARE-CFD fire model. It was found that the CFD model results were significantly improved and were in reasonable agreement with the experimental results. Significant discrepancies existed between the experimental results and the predicted results in the adjacent enclosures to the burn room because of the mixture-fraction formulation. Further research in this area is necessary to improve the overall predictions of a CFD model.

\section{ACKNOWLEDGMENT}

This research is supported by an Australian Research Council (ARC) Large Grant.

\section{REFERENCES}

1. Jones, W.P., and Whitelaw, J.H., "Calculation Methods for Reacting Turbulent Flows: a Review", Combustion and Flame, 48, 1-26, 1982 
2. Apte, V.B., Green, A.R., and Kent, J.H., "Pool Fire Plume Flow in A Large-Scale Wind Tunnel", The Proceedings of the 3rd International Symposium on Fire Safety Science, $425-$ 434, 1991

3. Sinai, Y.L., and Owens, M.P., "Validation of CFD Modelling of Unconfined Pool Fires With Cross-Wind: Flame Geometry", Fire Safety Journal, 24, 1-34, 1995

4. Fletcher, D.F., Kent, J.H., Apte, V.B., and Green, A.R., "Numerical Simulations of Smoke Movement from a Pool Fire in a Ventilated Tunnel", Fire Safety Journal, 23, 305-325, 1994

5. Chow, W.K., "Use of Computational Fluid Dynamics for Simulating Enclosure Fires", Journal of Fire Science, 13, 300-334, 1995

6. Lockwood, F.C., and Naguib, A.S., "The Prediction of the Fluctuations in the Properties of free, Round-Jet, Turbulent, Diffusion Flames", Combustion and Flame, 24, 109-124, 1975

7. Takeda, H., and Yung, D., "Simplified Fire Growth Models for Risk-Cost Assessment in Apartment Buildings", Journal of Fire Protection Engineering, 4:2, 53-66, 1992

8. Tsuchiya, Y., and Mathieu, J.F., "Heat, CO and Smoke Release Rates of Plywood under a Depleted Oxygen Atmosphere: An Experimental Study Using an OSU Heat Release Rate Apparatus", The Proceedings of the 3rd International Symposium on Fire Safety Science, 605-614, 1991

9. Boyd, R.K., and Kent, J.H., "Three-Dimensional Furnace Computer Modelling", The Proceedings of the 21 st Symposium (International) on Combustion, The Combustion Institute, 265-274, 1986

10. Luo, M. and Beck, V., "The Fire Environment in a Multi-Room Building - Comparison of Predicted and Experimental Results", Fire Safety Journal, 23, 413-438, 1994

11. Lockwood, F.C., and Shah, N.C., "A New Radiation Solution Method for Incorporation in General Combustion Prediction Procedures", The Proceedings of the 18th Symposium (International) on Combustion, The Combustion Institute, 1405-1414, 1980

12. Fernando, A., and Luo, M., "Modelling of Radiative Heat Transfer in Full Scale Building Fires", The Proceedings of the Australian Symposium on Combustion \& the 4th Australian Flame Days, The University of Adelaide, Australia, C3-3, November 9-10, 1995

13. Magnussen, B.F., and Hjertager, B.H., "On Mathematical Modelling of Turbulent Combustion with Special Emphasis on Soot Formation and Combustion", The Proceedings of the 16th International Symposium on Combustion, The combustion Institute, 719- 729, 1977

14. Woolley, W.D., and Fardell, P.J., "Basic Aspects of Combustion Toxicology", Fire Safety Journal, 5, 29-48, 1982

15. Cerra, A.P., and Ramsay, G.C., "A Protocol for Assessment of Smouldering Behaviour of Upholstery Combinations", DBR Report R85/2, Division of Building Research, CSIRO, Highett, Australia, 1985

16. Luo, M. and Beck, V., "Modelling Fire Behaviour in a Full Scale Building", The Proceedings of the 8th International Symposium on Transport Phenomena in Combustion, Paper No. 2-B-4, edit by Chan, S.H., Tayler \& Francis, 1995 